\title{
omuniação Popular: por uma genealogia do povo
}

\section{Eduardo Yuji Yamamoto 1}

Resumo: A partir do método genealógico desenvolvido por Friedrich Nietzsche (Genealogia da Moral) e apropriado por Michel Foucault (Genealogia do poder) em sua análise sobre o saber-poder nas ciências humanas, este artigo desenvolve alguns questionamentos acerca da pertinência de uma genealogia para o campo da Comunicação Popular. Toma-se como pressuposto a dispersão do conceito popular que caracteriza as inúmeras práticas comunicativas, validadas a partir dos modelos teórico-metodológicos das tradicionais ciências sociais. Demonstramos como tais modelos tornam-se insuficientes frente à atual configuração sócio-político-cultural, explicitada pela idéia de bios midiática. Como aporte teórico utilizamos o conceito de episteme e saber-poder de Foucault a fim de justificar o procedimento genealógico, além da noção de dialogia de Bakhtin para observar as mutaçōes do popular (enquanto signo refratado em práticas discursivas) no plano virtual da cultura. Por fim, explicitamos o papel da Comunicação Popular como configuradora das práticas comunicativas populares conforme sua delimitação de campo epistemológico legitimado. Ou seja, episteme capaz de responder os fenômenos insurgentes nesse campo.

Palavras-chave: genealogia, comunicação popular, epistemologia da comunicação, cultura popular, episteme

\begin{abstract}
From the genealogic method developed by Friedrich Nietzsche (Genealogy of the Moral) and appropriated to Michel Foucault (Genealogy of the power) in its analysis on knowing in sciences human beings, this article develops some questionings concerning the relevancy of a genealogy for the scienc of the Popular Communication. One is overcome as estimated the dispersion of the popular concept that characterizes innumerable the practical comunication, validated from the models theoretician-metodologic of traditional social sciences. We demonstrate as such insufficient models become front the current partner-politician-cultural configuration, idea from bios midiatica. As it arrives in port theoretical we use the concept of episteme and know-power of Foucault in order to justify the genealogic procedure, beyond the notion of dialogia of Bakhtin to observe the mutations of popular (while the sign refracted in discursive pratical) in the virtual plan of the culture. Finally, we explicit the paper of the Popular Communication as configured of the practical popular comunication as its delimitation of legitimated epistemologic. That is, episteme that answer the phenomenal in this field.
\end{abstract}

Jornalista graduado pela Universidade Estadual de Londrina (UEL), especialista em Comunicação Popular e Comunitária (UEL), e mestrando em Comunicação Midiática (linha de pesquisa: produção de sentido na comunicação midiática) pela Universidade Estadual Paulista (UNESP - Bauru, SP). Integrante do grupo de pesquisa "Mídia e Sociedade" (CNPq). Bolsista CAPES. 
“Nós, os investigadores do conhecimento, desconhecemo-nos. E é claro: pois se nunca nos procuramos, como havíamos de nos encontrar?" (Nietzsche, s/d: 5)

Em seu prefácio para a "Genealogia da Moral", Nietzsche dá início a uma questão bastante provocativa: o homem que busca o conhecimento deve, necessariamente, conservar-se ignorante de si. Tal paradoxo é descrito por uma necessidade de esquecimento ou negação das vivências humanas (e pessoais). Por curiosa ironia, o homem devotado pela missão de encontrar a verdade, permanece cego e surdo diante de si mesmo. Como se a procura pela verdade implicasse, concomitantemente, em sua ausência; ou, de outro modo, na existência de outras "verdades" paralelas.

Segundo Nietzsche, apenas retrospectivamente o homem pode (re)conduzirse, isto é, somente através da reflexão sobre aquilo que se passou, suas experiências ao longo de sua busca pelo conhecimento, é que o homem pode voltar a tomar posse de si.

De fato, a polêmica do filósofo gira em torno do problema da origem dos valores supremos da moral (cristã), que até então se colocavam como inquestionáveis. Longe de um sistema metafísico kantiano, Nietzsche argumenta que a verdade - e por efeito, tais valores - não é algo que deve ser achado ou buscado nos confins da história, mas algo que deve ser criado. Para ele, seria pura ilusão acreditar que a verdade permaneça imutável ao longo da história, ou das sucessões que parecem dar continuidade às formas de dominação desde o seu nascimento. Ao contrário, é na origem de tais valores, observa Nietzsche, que se define a sucessão de mal entendidos. Pois em sua gênese não se oculta uma verdade, ou uma identidade preservada de sua origem, mas a discordância com as outras coisas.

As questões levantadas por Nietzsche recaem sobre "as sobras" deixadas pela busca de uma verdade única que legitima uma forma de pensamento sobre todas as demais. Em cada momento da história, dirá mais tarde Foucault, a dominação se fixa em um ritual impondo obrigações, direitos, além de procedimentos e preconceitos.

Essa passagem é ilustrativa para compreender o lugar da Comunicação Popular na redefinição epistemológica de seu campo maior, a Comunicação. Nesse sentido, torna-se evidente que uma operação genealógica possa garantir a descrição de uma gama ampliada de manifestações populares, não para perscrutar origens ou delinear coerentemente um modo simplificado (ou simplista) de dominação histórica (como quer a genealogia tradicional), mas para avaliar as sobras da cultura, restos não-digeríveis pelos limites epistemológicos. Em outras palavras, as manifestações que extrapolam a episteme vigente, e que os modelos teórico-metodológicos tradicionais não nos deixam ver. A indicação de mutações sócio-culturais - o chamado bios midiático de Sodré (2002) -, definidas a partir de práticas comunicacionais generalizadas na esfera pública, apresenta a necessidade de "dispositivos de releitura das questões tradicionais da sociedade" (Sodré, 2003: 311) 2 Num território conflitivo como a da cultura popular, em que a dispersão parece diluir seu conteúdo e significado transformador, torna-se emergente a redescrição de interfaces dos fenômenos populares clássicos à luz das atuais práticas comunicativas. Tal preocupação se acentua na necessidade de um saber "ético- 
de negociação de poder, a participação dos excluídos no sistema de produção material e simbólico.

Assim, o que chamo de dispersão no campo da Comunicação Popular referese à variedade conceitual que a interpretação popular permite. Desde a comunicação realizada pelas bases da sociedade, dos chamados grupos excluídos ou dominados, passando pelas comunidades das mais variadas tribos - mesmo aquelas da internet -, ou ainda os veículos de comunicação que dão prioridade ao aspecto folclórico, exótico, inusitado de uma região. Entre elas, quanta diferença. Entretanto, o problema aumenta quando se tenta nomeá-las: Comunicação Popular, Alternativa, Livre ou Comunitária?

Como outra possibilidade de interpretação do popular (ou para acentuar uma crise de significado), o que dizer da qualificação jornalismo popular para designar um tipo de linguagem jornalística que se distingue pelo sensacionalismo (a exemplo da finada Notícias Populares)?

\section{Do popular: arbitrariedade, dispersāo e controle da palavra}

3 Muitos intelectuais pertencentes à geração de Foucault eram colocados em relação à Jean-Paul Sartre, posto a influência de seu pensamento existencialista. Não obstante, e dada a sua genialidade, Foucault escreve "As palavras e as coisas" como uma espécie de crítica ao humanismo - o vazio da essência, e sentido motivado pela existência - de Sartre, o qual apresenta uma não essencialidade das coisas e da própria existência humana. Esta idéia está contida na obra autobiográfica de Sartre intitulada "As palavras". A visão sartreana será, consequentemente, questionada por Foucault pela independência dos objetos (ou coisas) em relação ao conhecimento.

4 cessa visão de mundo, segundo Foucault, é marcada pela emergência da episteme moderna que irá substituir os saberes filosóficos ou ciência de representação por saberes do sujeito e do objeto: uma filosofia do sujeito transcendental e uma ciência do objeto empírico. É nesse contexto que o homem será pensado a partir de uma dupla posição: como objeto do conhecimento, e como sujeito que conhece. Assim, o homem irá ocupar o centro das problemáticas da história do saber. Não que na tradicional genealogia o homem não estivesse no centro dessas preocupações, mas que esse caráter se acentua ou torna-se uma constante na modernidade.
Em "As palavras e as coisas" 3, Foucault (1992) anuncia uma crise de representação do mundo clássico a partir de um questionamento do modelo disciplinar da verdade: até o final do século XVIII, o conhecimento era tributário de um saber, cuja representação era o próprio objeto. A noção de representação, calcada na episteme clássica, será questionada por Foucault, já que o objeto representado não se constitui como conhecimento empírico, mas como conjunto ordenado de signos.

\footnotetext{
Quando se considera um objeto nele mesmo e em seu próprio ser, sem levar o olhar do espírito àquilo que ele pode representar, a idéia que se tem é uma idéia de coisa, como a idéia da Terra, do Sol; mas quando só se olha um certo objeto como representando um outro a idéia que se tem é a de um signo, e esse primeiro objeto se chama signo. (Foucault apud Ternes, 1998: 79)
}

Na interpretação de Foucault, a modernidade é apresentada como marco a partir do qual tanto o homem $\mathbf{4}$ quanto a própria idéia de verdade científica serão desprovidos de um juízo absoluto. Interpretadas como um ordenamento sígnico, tais concepções se constituem em realidades restritas, ou mera representação do mundo em sua superfície visível. Suas construções anteriores são observadas como discurso sobre a verdade. Como conseqüência, o objeto se desvincula do conhecimento e a ciência passa a ser interrogada como objeto autônomo e universal.

Seguindo as trilhas abertas pela genealogia de Nietzsche, Foucault irá caracterizar os valores absolutos - como a moralidade ou a verdade científica enquanto concreção do discurso ou de uma potência em ato. Assim, toda afirmação de um real representado constituirá como manifestação de um poder subjacente à linguagem que outorga para seu campo de relação um status disciplinar e normativo. Com efeito, as questões científicas, estéticas e morais se reduzirão na genealogia niezscheana-foucaultiana a problemas de linguagem. Essa, em contrapartida, não possui justificativa ou fundamentação além de si mesma: como estrutura préexistente e mecanismo significante, a linguagem torna possível a materialização do signo ao exteriorizar um poder manifesto. 
[...] O que é uma palavra? A figuração de um estímulo nervoso em sons. Mas concluir do estímulo nervoso uma causa fora de nós já é resultado de uma aplicação fora e ilegítima do princípio da razão. Como poderíamos nós, se somente a verdade fosse decisiva na gênese da linguagem, se somente o ponto de vista da certeza fosse decisivo nas designaçōes, como podemos no entanto dizer: a pedra é dura: como se para nós esse "dura" fosse conhecido ainda de outro modo, e não somente como uma estimulação inteiramente subjetiva! Dividimos as coisas por gênero, designamos a árvore como feminina, o vegetal como masculino: que transposições arbitrárias! (Nietzsche, 1999: 55)

Tal arbitrariedade indica um modo aleatório de modelar os artefatos naturais e, assim, dar vazão às expressões humanas. Está impresso nesse ato o desejo da imposição de uma vontade, a latência do poder na aquisição elementar da linguagem. Assim, o signo passará a existir para os sujeitos da linguagem como fenômeno social. É através dos signos, em seu ordenamento em idéias e representações, que tais sujeitos constituirão seus sistemas sociais de valores, conceitos, etc. Imersos no campo das disputas sociais, seu caráter inicialmente neutro (ou individual), não mais existirá, deixando apenas os vestígios de uma conformação.

Os sistemas de valores predominantes, bem como as práticas sociais relacionadas às respectivas formações e práticas discursivas constituem formas da existência humana e expressam um poder negociado ou consentido. $\bigcirc$ exercício desse poder (e pensado não somente em sua evidência coercitiva), será produtivo na medida em que atende ou responde a um determinado conjunto de questões sejam elas de ordem ontológicas, ou de natureza mais objetiva (técnica-material). Entretanto, quando a sociedade se complexifica e exige outras maneiras de assegurar sua existência (física e psicológica), o poder deverá ser rearticulado em outras bases de sustentação. Esse fato irá denunciar a fragilidade um modelo vigente.

Tornar obsoleto os valores e conceitos que sustentam nossas certezas existenciais indica, além de seu alcance limitado, a necessidade de outros esquemas apreensivos. Frente aos desafios de se apreender fenômenos emergentes, a abertura ao novo torna-se necessária. $\bigcirc$ pressuposto de um novo esquema deverá ser esboçado a partir do questionamento do conjunto dos valores e conceitos usuais.

É nesse sentido que a genealogia nietzscheana-foucaultiana procurará

$5 \mathrm{Na}$ investigação dos fundamentos em que se baseia o conhecimento humano, Foucault (1992: 46) irá denominar episteme o conjunto de pressupostos e preconceitos que estruturam e demarcam o pensamento de uma época. Tal denominação é próxima da idéia de "paradigma", definida por Kuhn como "as realizações científicas universalmente reconhecidas que, durante algum tempo, fornecem problemas e soluções modulares para uma comunidade de praticantes de uma ciência“" (2006: 13). A aproximação desses dois pensadores se dá conforme a noção (ou negação) de verdade absoluta. Seja por paradigma (definida por Kuhn a partir de uma análise da ciência propriamente dita), seja por episteme, (insurgida na incursão de Foucault ao território da cultura, a partir de uma arqueologia das ciências humanas), o que deve ficar evidente é alteração no modo de pensar estabelecida por um novo modelo de pesquisa.

6

A verdade, relativizada de tal modo por alguns teóricos, será mote para um aprofundamento escapista que cerceará o pensamento de Nietzsche e Foucault até os dias de hoje. dissolver as fronteiras das verdades ética e científica, assentadas em bases rigidamente intocáveis ou absolutas. Colocar em dúvida determinadas certezas significa dizer que tais esquemas (teóricos, morais, etc) já não dão mais conta (ou tornaram-se obsoletas ou insuficientes) dos problemas de uma época.

Em sua crítica ao valor da verdade (ou porque é necessário acreditar em certos juízos), Nietzsche afirma que mesmo um juízo falso a respeito do mundo pode preservar a espécie humana e, no mais, servir como inspiração ou estimulo à vida. Do mesmo modo, Foucault explicita a validação do método histórico sem rupturas, a fim de garantir um discurso sobre a verdade e assim, preservar uma segurança interna a partir da ciência.

Entretanto, não se trata mais de buscar uma interpretação falsa ou verdadeira para na história do saber humano, mas de observar as condições que propiciam a emergência de determinada episteme $\boldsymbol{5}$, esquema apreendedor de uma visão de mundo, a qual a verdade depende para se impor (Foucault, 2003). É dessa forma, que a verdade $\mathbf{6}$ - como objetivo do conhecimento humano, mas também como desejo de poder sobre o mundo - será tratada em Foucault como justificativa de um exercício institucional do poder, através de seu conhecido "saber-poder".

Expresso em âmbito epistemológico, o poder deixa entrever modos de dominação que não se esgotam absolutamente nesse campo, como mero produto da reflexão de valores, idéias e conceitos. Sua base está assentada na dinâmica da 
sociedade a partir da qual se pode observá-la como fruto de um intercâmbio social. É a prática social, matéria-prima do pensamento reflexivo, a materialidade própria do poder. É somente a partir das ações do homem em sua coletividade e interação, que as relações anteriormente explicitadas fazem algum sentido.

\section{Produção e reprodução do popular no campo das disputas sociais}

7 Embora Foucault ressalve o pensamento ideológico como falsa consciência, a idéia de discurso ideológico ilustra as relações de poder intrínsecas no campo das interações sociais. Segundo ele, "A noção de ideologia parece dificilmente utilizável por três razões. A primeira é que, queira ou não, ela está sempre em oposição virtual a alguma coisa que seria a verdade. Ora, creio que o problema não é de se fazer partilha entre o que num discurso revela a cientificidade e da verdade o que revelaria de outra coisa; mas de ver historicamente como se produzem efeitos de verdade no interior do discurso que não são em si nem verdadeiros, nem falsos. Segundo inconveniente: refere-se necessariamente a alguma coisa como o sujeito. Enfim, a ideologia está em posição secundária com relação a alguma coisa que deve funcionar para ela como infraestrutura ou determinação econômica, material, etc. Por estas três razões creio que é uma noção que deve ser utilizada sem precauções." (Foucault, 1999: 7)

8 . unça coextensiva da linguagem conforme a "palavra de ordem" explorada por Deleuze e Guatari em Mil platôs: "Os jornais, as notícias, procedem por redundância, pelo fato de nos dizerem o que é 'necessário' pensar, reter, esperar etc. A linguagem não é informativa nem comunicativa, não é comunicação de informação, mas - o que é bastante diferente - transmissão de palavras de ordem, seja de um enunciado a um outro, seja no interior de cada enunciado, uma vez que o enunciado realiza um ato e que 0 ato se realiza no enunciado." (1995: 16)
Como prática social, a palavra carrega as designações de um grupo que the impinge significações conforme seus respectivos sistemas de representações, ou formações ideológicas. Bakhtin (1997: 36) define a palavra como signo ou "fenômeno ideológico $\mathbf{Z}$ por excelência", fruto das interações humanas. Consequentemente sua dinâmica será determinada pelos confrontos travados no palco das disputas sociais. Essa negociação se dá, literalmente, pelo 'domínio da palavra'.

Observa-se, entretanto, que o produto deste embate irá definir modos de controle da palavra 8 que operam sob um duplo movimento de complementaridade: ora pela subsunção no campo do significado, ora pela saturação ou "tautismo" (SFEZ, 1994). Por um lado, como forma de se preservar/paralisar determinado sistema de representação, suprime-se do campo semântico àquilo que ela tem de mais perigoso (em nosso caso, a idéia de popular que carrega as aspirações de uma dialética social). Por outro lado, observa-se que é nesse caos sígnico que se verifica uma forma de dominação pelo controle. Nesse caso, ela se configura pela saturação do signo e economia do significado.

Nesse mecanismo de linguagem se evidencia uma atitude normativa que irá tender a uma simplificação das práticas comunicativas populares, a partir do controle de sua dispersão. As práticas sociais, desse modo, deverão permanecer subordinadas ou controladas em graus de periculosidade, conforme o alcance desse condicionamento. Isso não significa uma reificação do significado, isto é, que as regras da língua sejam determinantes na produção ou totalização humana, o que acarretaria um congelamento do sujeito em sua estrutura. Entretanto, pode-se afirmar que o controle do significado, em determinado período, revela uma forma de dominação, como produto histórico, socialmente constituído.

Observar este modo de dominação pelas lentes de Foucault (1999) significa desvencilhar-se de uma metafísica finalista, ou de uma reprodução automática e estagnada da cultura popular. Nesse sentido, a dominação atuando através da subordinação da palavra deixa entrever, não um domínio unidirecional ou verticalizado, mas em níveis elementares, diferenciados, e em variados pontos da rede social. Para ser consentido o poder deverá ser socialmente exercido nos diversos níveis (horizontal e vertical) da estrutura social. Nessa complexa trama, ele poderá existir ou não integrados a um poder centralizador.

Como dissemos, o poder é produtivo não apenas devido à sua tecnologia civilizatória, mas também na medida em que é rearticulado em bases outras. Afirmar a reprodução pura e simples de uma lógica vertical de dominação é negar o potencial ressignificativo e dialógico da cultura. Bakhtin observa que "o ser, refletido no signo, não apenas nele se reflete, mas também se refrata” (1997: 48). Essa compreensão assegura a ampliação da natureza refrativa do signo, a partir da produção do novo. Tal processo se dá pela rearticulação do signo na base da cultura ressignificada, e expressa em práticas discursivas. Esse engendramento deverá contribuir para a dispersão do espectro popular. 
Em âmbito epistemológico, o poder terá uma expressividade normativa semelhante à técnica de controle social, atuando como dispositivo tecnológico e regulador do pensamento. Na condição de tecnologia fornece perguntas e respostas acerca dos fenômenos inquietantes de uma determinada época. Como normatização garante a coerência interna do sistema social de pensamento.

Em Comunicação, o caráter tecnológico e normativo de sua episteme garantirá um período de serenidade do campo (em parte devido à coerência teóricoconceitual de suas definições mais elementares tributárias, essencialmente, das tradicionais ciências sociais e que respondem às demandas gerais deste momento histórico). Entretanto, frente às modificações no plano cultural, segundo o acionamento de "dispositivos econômicos, sociais e políticos" (Chauí, 1982: 6) de um período, passam a configurar novos fenômenos como aqueles propriamente comunicativo 9.

Consequentemente, em Comunicação Popular podemos dizer que algumas destas implicações são justas a começar pelo discurso sedimentado nos veículos digno desta denominação: são populares por que? Há uma essencialidade (ou consenso), em comunicação, no sentido popular? Ou constitui apenas uma estratégia política, proselitista? Quais as relações de poder (ou os contrato comunicacionais implícitos) estabelecidas na sociedade, em nome do povo? E quais as práticas comunicativas que permanecem ausentes de todo este enquadramento?

Em meio a um cenário de constantes modificações podemos localizar um novo sujeito social (ou objeto), antes relegado como ator coadjuvante pelas tradicionais disciplinas: os veículos populares de comunicação. A idéia de sujeito, nesse caso, afirma a emergência de um corpo autônomo que perambula pela sociedade contemporânea, produz discursos e designam uma representação sem representação de fato, passando a existir em si e para si. Criam fatos midiáticos (a exemplo dos próprios canais de comunicação comunitária, e do televisivo circo de horrores destinados aos grupos que levam como uma sina a denominação de povo), e passam a viver num grande palco de encenações. Vivem numa legitimidade próxima à idéia de ideologia, embora numa dinâmica muito mais complexa, já que assentam não mais no "instituinte ou histórico", ou "institucional instituído", (Chauí, 1982: 5) mas paralelamente a tudo isso, em suas sobras indigestas.

A legitimidade desses veículos populares também pode se assentar na imagem que esses têm hoje em dia. Assim, a expressão Comunicação Popular pode nos remete à impossibilidade classificar como legítimas manifestações institucionais a exemplo da Comunicação Comunitária. Mas talvez não seja esse o caso, pois já não há um caminho único para a utopia.

A compreensão desses mecanismos de representação e poder se dá na superfície concreta dos fatos, em práticas sociais generalizadas, em micro-ações cotidianas: poderá, assim, aplicar-se às posições deliberadamente assumidas, por exemplo, por aqueles (veículos) que se julgam do povo, ou pertencentes ao povo,

Tal fenômeno pode ser ilustrado pela idéia de "dispositivo semiótico tecnologizado simulador da realidade“ que segundo Sodré (2003: 308 - 309) seria ocasionado pelo advento da mídia como ator social, alterando os modos tradicionais de se pensar a organização humana: "a mídia vive do discurso que faz sobre sua própria simulação das outras realidades. Não se trata de discurso sobre representação de substâncias históricas, mas de discurso sobre discurso." tal qual em identidades atribuídas, isto é, naquelas imagens que se tem desse 'outro' delimitado em seu espaço político-cultural e em suas características estéticas. Pode ainda se caracterizar pelo inclassificável, o interdito (ou não dito). 
Para explicitar melhor o que tenho chamado de dispersão do popular na Comunicação, convém observar um esboço sistemático deste quadro, a partir das vertentes teóricas que o campo até então vem se fundamentando. Enquanto conceito dialético de povo, Peruzzo utiliza a denominação "popular-alternativo". Este, segundo a autora,

\footnotetext{
Situa-se no universo dos movimentos sociais populares num processo dinâmico de lutas por seus direitos. Mas há outras dimensões do popular, como popular- folclórico, abarcando as manifestações culturais tradicionais e genuínas do "povo" presentes em manifestações de folkcomunicação (literatura de cordel etc.); e como popular-massivo. Este se manifesta em três dimensões: culturalista, popularesca e de utilidade pública. (2004: 116)
}

Observa-se que essas três tipologias surgem para dar conta da dispersão que caracteriza as práticas populares de comunicação. Entretanto, elas vêm como categorização (conjunto teórico-conceitual) das tradicionais ciências sociais. Num primeiro momento acaba por plasmar o campo da Comunicação trazendo a contribuição de seus modelos teórico-metodológicos; Posteriormente, fixam raízes e arrastam o campo da Comunicação às epistemes já gastas das velhas disciplinas.

Parafraseando Nietzsche, podemos dizer que os modelos (morais, mas em nosso caso teóricos-metodológicos) que se caracterizam pelo perscrute na história (ou na genealogia tradicional) de um fim que se justifiquem em si e por si, constitui "um estágio que a humanidade deverá necessariamente experimentar e a atravessar". E é neste movimento, de reflexão e auto-crítica, que se baseia a genealogia nietzscheana-foucaultiana.

Entretanto, isso não significa que os construtos teóricos da Comunicação sejam desprovidos de valor. Conforme Nietzsche, este constitui um percurso necessário. Seria bastante negligente desqualificar os construtos que durante muito tempo orientou, ética e profissionalmente, os agentes da mídia, ao revés dos impulsos políticos do mercado.

Por outro lado, seria retrocesso determo-nos em velhos paradigmas quando a bios midiática se transforma, impõem novos enigmas, produz discursos sobre si expandindo os limites da nossa cultura e interpretação. Como a Comunicação Popular poderá lidar com essas mudanças?

Comunicação Popular, Alternativa, Livre ou Comunitária? Aparentemente pode parecer que estamos falando de coisas diferentes, embora todas elas se restrinjam a um mesmo denominador. Devemos encarar a Comunicação Popular como ferramenta de emancipação do homem? Ou tomá-las como sinônimas (o que é bastante recorrente nesse campo), e acreditar que a institucionalização da Comunicação Comunitária possa vir a ser uma conquista popular?

Sob a ótica foucaultiana, podemos observar que a institucionalização da Comunicação Comunitária, longe de qualquer celebração popular (ou ilusão de uma conquista histórica), representa a normatização e o controle do sujeito comunicativo. Este quadro, entretanto, pode talvez soar apocalíptico se ainda nos contermos às tradicionais teorias. Para ilustrar uma outra forma de abordar este problema vamos observar um fato bastante recorrente em Comunicação Comunitária: trata-se das práticas comunicativas em que não estão pressupostas a participação da comunidade, tanto menos a estimulam ou a representam.

Em primeiro lugar, podemos retomar a noção de controle pela palavra e aí dizemos equivocadamente que a expressão Comunicação de Popular foi substituída pela Comunicação Comunitária já que, aparentemente, ambas parecem sinônimas. Entretanto, se considerarmos que o popular implica mudanças estruturais na 
sociedade, deduzimos a meticulosidade como esta palavra foi estrategicamente subsumida no comunitário. Porque popular, pelo menos na acepção que foi suprimida, designa participação, movimento, utopia, qualidades contrárias à ordem vigente. Já comunitário, como solidariedade, pertencimento, afeto, calor, do modo como vem sendo utilizado nos dias de hoje, não oferece qualquer risco ao sistema. Ademais, hoje, tudo é comunidade: não existem mais classes antagônicas, mas grupos (variados) de oposição.

Nesse caso, podemos dizer que a Comunicação Popular deva ser redescrita. $\mathrm{O}$ exemplo acima ilustra as possibilidades conceituais de popular, mas não defini (e também nem é o caso) terminantemente.

O desenvolvimento de uma genealogia do povo em Comunicação, ainda que como anti-ciência, deixa entrever os mecanismos de um saberpoder que hierarquiza e subjulga idéias, conceitos e práticas discursivas lançando mão de tantas dimensões de um fenômeno.

O "controle da palavra", nesse caso, entra em conformidade com a constituição do campo epistemológico ao mesmo tempo em que garante uma forma de controle social. Com efeito, a normatização será a garantia de continuidade de uma mesma ordem política.

Como dissemos ao longo deste artigo, o procedimento genealógico deverá buscar em sua gênese não uma origem que justifique um caminho, ou ofereça ao povo uma verdade sobre si ao buscar na história sem rupturas uma legitimidade para tal, uma verdade ocultada em sua origem, uma gênese divina, primordial. Entretanto, a genealogia deverá fixar-se nas várias gêneses que compõem sua origem. Como Nietzsche bem salientou, o que a história faz é inverter o dispositivo genealógico colocando o fim na origem. É a vontade de potência que se coloca na definição da origem dos valores e conceitos; pois o que realmente existe em sua origem é nada mais que o discurso sobre a origem. A busca da verdade, segundo o pensamento do filósofo, é justificável na busca existencial humana, pois aumenta nossa sensação de poder sobre o mundo.

Ao questionar Kant sobre a possibilidade de juízos sintéticos a priori, Nietzsche se pergunta: por que nos é necessário acreditar em juízos a priori? Esse juízo pode ser falso e ao mesmo tempo estimular a vida e preservar a espécie humana. $\bigcirc$ que se coloca em questão, entretanto, não é se tais interpretações sobre o mundo sejam verdadeiras ou falsas - é impossível saber em absoluto -, mas que elas desenvolvem uma vontade de poder em direção ao controle. Coloca-se desse modo, um desafio à Comunicação Popular: qual seja, a descrição dos fenômenos comunicativos populares tradicionais - verdades calcadas nas epistemes de um período histórico - à luz de suas atuais manifestações.

Talvez à objeção "O que é Comunicação Popular nos dias de hoje?" respondida numa tacada só, acabe por resolver os problemas gerais da Comunicação Social: a definição de campo e objeto. Para tal, a máxima socrática permanece atual: "Conhece-te a ti mesmo". 
AMARAL. Márcia (2006). Jornalismo popular. São Paulo: Contexto.

ANGRIMANI, Danilo (1995). Espreme que sai sangue. São Paulo: Summus.

BACCEGA. Maria Aparecida (2003). Palavra e Discurso: História e Literatura. São Paulo: Ed. Ática.

BAKHTIN. Mikhail (1997). Marxismo e filosofia da linguagem. São Paulo: Hucitec. CHAUÍ, Marilena (1982). Cultura e democracia: o discurso competente e outras falas. São Paulo: Moderna.

DELEUZE, Gilles; GUATARI, Félix (1995). Mil platôs. Capitalismo e esquizofrenia. Vol. 2. Rio de Janeiro: Editora 34.

FOUCAULT, Michel (1999). A microfísica do poder. Rio de Janeiro: Graal. (1992).As palavras e as coisas. São Paulo: Martins Fontes. (2003). A arqueologia do saber. Rio de Janeiro: Forense

Universitária. (2004). A ordem do discurso. São Paulo: Ed. Loyola.

GIACÓIA JÚNIOR, Oswaldo (2001). Nietzsche. Para a genealogia da moral. São Paulo: Scpicione.

KUHN, Thomas S (2006). A estrutura das revoluções científicas. São Paulo: Perspectivas.

NIETZSCHE, Friedrich. (s/d) A genealogia da moral. Lisboa: Guimarães \& Cia editores.

(1999) Sobre verdade e mentira no sentido extra-moral. In:: Obras incompletas. São Paulo: Nova Cultural.

PERUZZO, Cicilia M.K. (2004). Comunicação nos movimentos populares. a participação na construção da cidadania. Petrópolis: Vozes.

SFEZ, Lucien (1994). Crítica da Comunicação. São Paulo: Loyola.

SODRÉ, Muniz (2002). Antropológica do espelho. Petrópolis: Vozes.

(2003). Ciência e Método em Comunicação. In: LOPES, Maria Immacolata V. de. (org.) Epistemologia da comunicação. São Paulo: Edições Loyola.

TERNES. José (1998). Michel Foucault e a idade do homem. Goiânia: Ed. UCG 